\title{
Deinstitutionalization in the USA*
}

\author{
Leonard Fagin, Consultant Psychiatrist, Claybury Hospital, Woodford Green, Essex
}

The task of summarizing the experience of public mental hospitals in the USA is perhaps impossible and unrewarding as far as UK-based psychiatry is concerned. The complex governmental and insurance intrastructure, the heterogeneity of approaches and the disappointing rhetorical stance one observes in learned journals make it difficult to translate American practice to our own. This task is even more difficult when one only has written communications to fall back on, and readers will have to take this into account in this brief article.

Historical overview of public mental hospitals in the USA'

The first public hospital in the US opened in 1773, in Williamsburg, Virginia and followed in concept the 'era of moral treatment' ushered by Pinel's removal of patients' chains in the Salpetrière in Paris. This thirty-bedded hospital was seldom filled and concentrated on re-educating the disturbed patient in a 'proper' environment. The hospital culture was homogeneous, consisting of middle or upper class patients whose care was paid for by their families. Treatment included three to four hours per day of leisure activities, social gatherings and educational and religious lectures, and patients were expected to return to the care of their families. They boasted 'cures' of 70 per cent and this prompted demands for State provision on the same lines. Other hospitals in eastern cities were soon to follow-in New York, Philadelphia and Boston-never housing more than 200 patients. By the middle of the 19th century, twenty-five hospitals were in operation, with less than 3,000 beds in total. By the turn of the century the combination of rapid urbanization, industrialization and European immigration brought many newcomers to institutions, which soon became overcrowded. New State hospitals were built, housing thousands of patients, with the well-meaning aim of separating the poor and the foreign mentally ill from the rest of the community, and at minimal cost. By this time therapeutic optimism had given way to acceptance of custodial care on a permanent basis for mental patients who were seen to be suffering from incurable degenerative nervous system illnesses. By 1900,100 hospitals had been built, and at their peak in 1955 , there were 350 with a resident population of approximately 560,000 .

It is interesting to observe that some of the factors explaining the growth of these institutions were also arguments used to promote their demise: (i) the zeal of reformers, like Dorothea Dix, crusading for care of the mentally ill regardless of means; (ii) the growth and changing economy; (iii) massive immigration; (iv) society's need to isolate deviant and disturbing behaviour; and (v) the optimistic view that under proper supervision human behaviour was susceptible to change.

Deinstitutionalization rapidly began in 1955 when the

- Paper presented in June 1984 to the Psychiatric Advisory Committee, North East Thames Region sponsored conference on 'Closure of Psychiatric Hospitals'. figures of resident patients first began to decline. This was partly promoted earlier on by the creation of the National Institute of Mental Health in 1946, under President Truman, and by a number of hospital scandals which led President Eisenhower, in 1955, to ask the National Institute of Mental Health to report on the provisions for the mentally ill by the Joint Commission on Mental Illness and Health. By 1977, there were 160,000 patients in public mental hospitals, a drop of 400,000 (71 per cent) in just two decades. Without going into detail, the factors underlying this massive change, which paved the way to a community care emphasis, included: (i) the emergence of psychoanalytic thought-mental illness could now be understood, and therefore those suffering from it helped through insight and a supportive therapeutic relationship; (ii) World War II introduced the notion that brief, intensive care on the front could ensure a soldier's rapid return to duty; (iii) society's concern at the cramped conditions in Veterans Administration and state hospitals and an increasing demand to improve the care of their residents; (iv) the concept of institutionalization as a factor which contributes to social incompetence and apathy among patients; $(v)$ the advent of effective psychopharmacology; and (vi) the social justice movement of the early 1960 s challenging the legality of detention under the US constitution.

Heralded in 1961 by President Kennedy's call for the closure of large institutions and their replacement by a home community care service, Congress enacted legislation in 1963 , called the Community Mental Health Centres Act (Public Law 88-164), whereby National Government would provide initial grants for the establishment of a community-based care system around a network of mental health centres. The Community Mental Health Centres had the lofty aims of in-patient and out-patient services, partial hospitalization, emergency services, consultation and education, out-patient maintenance of chronic patients to be discharged and accessibility for lower class patients to out-patient provision. In fact, growth of out-patient services has been the most striking feature of the mental health scene in America. In 1955, for example, 27 per cent of mental health care was provided in out-patient facilities and 73 per cent in-patient. By 1975, the situation was almost completely reversed: 70 per cent was out-patient, 27 per cent in-patient and 3 per cent day care.

Following these developments, the process of deinstitutionalization was hurried on by State Governments, many of which no doubt saw fiscal advantages to large-scale hospital discharges and the closure of expensive, antiquated facilities. As was true with many social changes, the new programme followed administrative fiat rather than the result of controlled, carefully performed experiments or changes and ideas arising from professionals working in the field.

\section{Process of deinstitutionalization}

The National Institute of Mental Health defined deinstitu- 
tionalization as: (1) the prevention of inappropriate mental hospital admissions through the provision of alternatives for treatment; (2) the release into the community of all institutionalized patients who have been given adequate preparation for such a change; (3) the establishment and maintenance of community support systems for non-institutionalized people receiving mental health services in the community.

Although there has been a shift in American attitudes towards the closure of large institutions, and the general public and mental health professionals have accepted the idea, if not the reality, of mentally ill people in the community, this acceptance appears to be as a value, as a concept. Deinstitutionalization is all right as long as it takes place in someone else's neighbourhood. Nonetheless, the 'community', whatever this woolly and ill-defined notion may be, is now considered a better place for the mentally ill, and hospitalization is frowned upon, whilst discharges and brief admissions, especially if they produce a lower in-patient census, approved of. The discharge rate, as a result, increased by the early 1970 s to 10 per cent per year, slowing down in the late $1970 \mathrm{~s}$ as the hard core of dependent patients proved to be difficult, if not impossible, to move to appropriate or suitable alternatives.

Long-term patients aged 65 and over have contributed mostly to this decline and their admission rate has also been lowered. Most of them are now in nursing homes, where the proportion of elderly residents with a mental disorder has increased dramatically. In $1974,85,000$ people who had formerly been in mental hospitals were in nursing homes. ${ }^{2}$ Of the 1.3 million residents in nursing homes surveyed in $1977,{ }^{3}$ 250,000 (19 per cent) had a primary diagnosis of mental disorder whilst 100,000 others had a diagnosed psychiatric condition (7.7 per cent). Many of these would have been in psychiatric hospitals had a policy of deinstitutionalization not taken place. This move towards nursing home care did not necessarily entail better care. Some have described them as the new back wards in the community, and worryingly studies have shown that mixing psychotic and physically disabled has not been conducive to improvement. Higher usage of tranquillisers has been observed, not only for psychotic patients, to keep residents more docile. In the younger groups, few were able to graduate to independent living or sheltered employment. ${ }^{4}$

\section{Reactions and effects of deinstitutionalization}

Despite this move towards deinstitutionalization, it would be careless to assume that there has been a consensus in the US to the closure of hospitals. Although 78 hospitals had closed in the 1970s, few have done so submissively or without considerable complications.

One of the rallying arguments given against the closures is economic. As an institution, the hospitals play an important part in each State's economy. The hospital staff and patients purchase goods from local businesses. The hospital employees, especially those who are middle-aged and have worked there for a long time, have used the local trade unions and politicians to represent them in their opposition to a change, partly because they have no other trade, and their fear of unemployment is therefore serious and realistic. Matters then become highly-charged political issues. In California, for example, the State Legislature passed a Bill preventing the closure of any public mental hospitals without the Legislature's prior approval, which ordinarily would have been the discretion of the Governor. Governor Reagan vetoed the Bill, but the Legislature overrode his veto by a twothirds majority.

Another point for opposition is the location of the sites suggested for alternative care. Schulberg $e t a l$ indicated that abstract expressions of support for this policy rapidly evaporate when citizens realize that the residences are likely to be in their midst, expressing fears of sexual and physical violence, bizarre behaviour, lowering of land values, noisy disruptions and destruction to property. As a result some communities have implemented 'zoning restrictions' where no mentally ill residents may move to, so the location of these residences are more likely to be in poor areas, where rents are low and often social disorganization high.

This opposition has also been helped by lack of necessary funds to develop community facilities. Whilst the numbers of patients have declined, expenditures in the hospitals have not, and money is therefore not following the patient out of hospital. Despite expectations to the contrary, public expenditure (in constant dollars) was higher in 1975 than 1971, mostly because of transitional costs, such as maintenance of facilities at minimal level to prevent deterioration, costs of alternative services and re-training of personnel. Furthermore, insurance services do not cover many community facilities needed by discharged patients, other than nursing-homes, thus explaining why these are the preferred mode of release from hospital.

To add to this, recent studies have shown that public hospitals are still the only choice of facility when it comes to socially deviant, disruptive individuals, and now issues of violence involve 60 per cent of admissions, with hospital patient populations becoming skewed towards this type of patient. ${ }^{6}$

Comprehensive research into the effects of hospital closures has been conspicuous for its absence, although some studies of individual closings are worth mentioning. A recent review' has found only a few such studies which meet the criteria of randomization, control groups, broad range of variables of outcome and adequate sampling size and length of follow-up. The projects by Linn et al, ${ }^{\mathrm{R}}$ introducing the concept of foster care for chronic patients, and Weinman and Kleiner,' where community placements were well supported with 'socio-environmental therapy', indicate that where comprehensive and intensive planning takes place the efforts are more likely to be met with success in terms of breaking the pattern of revolving-door admissions, increasing self-esteem and encouraging independence. Where this has taken place, the reviewers conclude, alternatives to long-stay care are feasible, and at worse, fare no less well than traditional hospital practices. This is especially so if the alternatives include a wide range of services, including psychiatric, residential, vocational, social and medical back-up. Where should the onus of proof be? Should non-hospitalization advocates prove that community care leads to improvement, or if those alternatives 
provide a less restrictive environment than the institution, should they at least fare no worse?

Research done by the National Institute of Mental Health has also concluded that closures can be carried through without major economic consequences. The Modesto State Hospital was the first to close in California in 1970. The economic status in the area was studied and no adverse effects were observed in terms of economic activity or unemployment. The closure of the De Witt Hospital in 1972 accounted for a loss of approximately 10.4 million dollars which did not have a great impact on the regional economy. However, at the time the general regional economy was growing. Another factor to be taken into account is the speed of the closure. Gradual closures allowed adjustments to be made, and this alone justified attempts at resisting time tables imposed by the administration.

Although public reaction was often fierce, it was less vociferous where public meetings took place, which emphasized the advantages of community care and reduced public anxiety by explanation and communication. Staff apprehension was diminished by offers of alternative employment in the new service, early retirement, job counselling or help with re-employment services and re-location, re-training and compensation for moving expenses.

The psychological effects of hospital closures are very similar to those observed in unemployment-a short period of denial with a refusal to react and plan for the future, followed by a replacement with anger and anxiety with attempts to reverse the decision or at least delay its implementation, and a tendency to overlook the defects of the institution and magnify its virtues, and finally resignation or at best, coming to terms with changes in expectations. During this process patient care was observed to suffer, making it difficult to sustain staff morale and optimistic expectations when they appeared to be most needed. According to Kram" patients began to act out, became more apathetic and resistive to treatment. Where discussion between staff groups occurred, and where participation in decisions and planning took place, a portion of this damage was reduced, especially if feelings of loss and frustration were shared.

Where this had not taken place, and where adequate community provision had not accompanied closure with the necessary breadth and speed, newspaper headline disasters brought to public attention stories of aimless, wandering and homeless people who were easily victimized by unscrupulous and opportunistic landlords $-6,000$ patients homeless in New York alone. Other institutions, especially prisons, often provided the shelter that had been denied to those who needed it. leading some experts to talk about 'transinstitutionalization' rather than 'deinstitutionalization'.

It is outside the scope of this paper to discuss the Community Mental Health Centre movement, whose development preceded and accompanied deinstitutionalization. The reaction from medical professionals is united in agreeing that as a result of closures, Community Mental Health Centres have been overwhelmed by the total responsibility of psychiatric services which has been thrusted on them, and not surprisingly often fail to provide these when State funds are not forthcoming. Some medical professionals have also found themselves ostracized and de-roled from their traditional hierarchial status. This was more readily accepted in the context of a hospital environment, but challenged when working in the community where staff insisted on working in multidisciplinary fashion. Many psychiatrists, fed up with the role of 'prescription-pushers' that others had allocated to them, retired and withdrew back into institutions and private care, often criticizing Community Mental Health Centres for being social welfare agencies rather than health facilities, and for rejecting care to those 'most deserving'. Others, who braved the initial changes, have found Community Mental Health Centres ideal venues for co-ordination of community psychiatric services, frameworks for preventive mental health work and opportunities for creating a primary mental health facility which links up primary general health care and in-patient and rehabilitation psychiatric care.

It is fair to say that for many in the UK these notions are still very difficult to accept, let alone to envisage in practice. It is difficult to say at this stage whether history will adjudge the American experience a success, or simply another innovation which the fickle mental health movement has had to endure in its history of turnarounds. What is important to us here in the UK is that the writing is already very much on the wall for many of our Victorian institutions, and we can only ignore the experience of our American colleagues at our peril.

REFERENCES

IFeldman, S. (1980) Public mental hospitals-The American experience. Paper presented at the Mind Annual conference on 21 October 1980.

2Goldman, H. H., Adams, N. H. Taube. C. (1983) Hospital and Community Psychiatry, 34, 129.

${ }^{3}$ Returning the Mentally Disabled to the Community (1977) Summary of a report. US General Account Office-January 1977.

4 LAMB, R. H. (1979) The new asylums in the community. Archives of General Psychiatry, 36, 129-134.

SSchulberg, H. C., Becker, A. McGrath, M. (1976) Planning the closedown of mental hospitals. Community Mental Health Journal, 12(1), 176-181.

'Lamb. R. H. (1977) The State Hospital: Facility of last resort. American Journal of Psychiatry, 134, 10, 1151-1152.

'Braun, P. . Kochansky, G. . Shapiro, R., Greenderg, S., Gudeman, J., Johnson, S. \& Shore. M. (1981) Overview-Deinstitutionalisation of psychiatric patients: A critical review of outcome studies. American Journal of Psychiatry, 136, 736-749.

'Linn, M. W. . CAffey, M. JNR., KLetr. C. J. et al (1977) Hospital vs. community (foster) care for psychiatric patients. Archives of General Psychiatry, 34, 78-83.

9Weinman, B. \& KLeiner, R. J. (1978) The impact of community living and community member intervention on the adjustment of the chronic psychotic patient. In Alternatives to Mental Hospital Treatment (ed. L. I. Stein). New York: Plenum Press.

10KRAM, L. (1973) Closing an institution: Its effect on patients and staff. Hospital and Community Psychiatry, 26, 1 April. 